\title{
Title: Medical teachers conceptualize a distinctive form of clinical knowledge
}

\section{Running Title: Medical teachers and clinical knowledge}

\author{
Authors: \\ Dr J. Barrett \\ Prof L. Yates \\ Prof G. McColl
}

Affiliation: The University of Melbourne

\section{Correspondence:}

Dr J. Barrett

Faculty of Medicine, Dentistry and Health Sciences

The University of Melbourne

Victoria, Australia 3010

Phone: +61 417546840

j.barrett@unimelb.edu.au

\section{Medical teachers conceptualize a distinctive form of clinical knowledge}

J Barrett, L Yates, G McColl

\begin{abstract}
For over four decades, there have been efforts to specify the types of knowledge that medical students need, how that knowledge is acquired and how its constituent parts are related. It is one of the areas of continuing concern underlying medical education reform. Despite their importance to medical students' learning and development, the perspectives of medical teachers in hospitals are not always considered in such discourse. This study sought to generate an understanding of these teachers' values, perspectives and approaches by listening to them and seeing them in their everyday teaching work, finding and understanding the meanings they bring to the work of medical teaching in hospitals. In interviews, all of the teachers talked more about the optimal forms of knowledge that are important for students than they talked about the form of the teaching itself. Many revealed to students what knowledge they do and do not value. They had a particular way of
\end{abstract}


thinking about clinical knowledge as existing in the people and the places in which the teaching and the clinical practice happen, and represented this as 'real' knowledge. By implication, there is other knowledge in medical education or in students' heads that is not real and needs to be transformed. Their values, practices and passions add texture and vitality to existing ways of thinking about the characteristics of clinical knowledge, how it is depicted in the discourse and the curriculum and how it is more dynamically related to other knowledge than is suggested in traditional conceptualizations of knowledge relationships.

\section{Key Words}

Clinical knowledge, clinical teaching, medical teachers

\section{Medical teachers conceptualize a distinctive form of clinical knowledge}

\section{Background}

The meaning of the term 'clinical knowledge' is often presumed rather than explicitly defined in the medical education literature both in the context of empirical studies (Vosti et al., 1997) and theoretical papers (Malterud, 2001). The implicit understanding is either made clear or more easily interpreted in reports of studies in which 'clinical' and 'bioscience/biomedical' knowledge have been compared and contrasted for particular purposes. 'Clinical knowledge' is usually understood to entail 'information about relations of particular signs and symptoms with specific diseases' (de Bruin et al., 2005 , p. 765). For Irby, with a focus on teaching, the classification of 'clinical knowledge' was part of an extensive and influential programme of research with medical teachers. Irby generated a model of six domains of knowledge including essential aspects of communication that he had identified.

Figure 1: Domains of clinical knowledge (Irby, 1994)

\begin{tabular}{|c|c|}
\hline Medicine & Groups of patients \\
\hline Learners & General principles of teaching \\
\hline Individual patients & Case based teaching scripts \\
\hline Communication: compassion, sensitivity, intuition \\
\hline
\end{tabular}

There have also been programmes of research focused on the relationships between different forms of knowledge and the relative status of each form. According to Patel's 'two worlds' model, 
experienced doctors are seen to separate bioscience knowledge from their clinical knowledge and the two worlds interact only minimally in the doctors' practical reasoning (Patel et al., 1989). From another perspective, the so-called 'encapsulation' model of medical knowledge suggests that formal bioscience knowledge becomes gradually integrated through repeated application in a clinical context (Rikers et al., 2005). Non-biomedical knowledge from the basic sciences (including physics) contributes to the causal information that students need for interpreting clinical details (Goldszmidt et al., 2012), and has been shown to provide students with something of 'an organizing conceptual framework in learning clinical medicine' and therefore having a 'developmental role' for the learners (Woods, 2007, p. 454). Woods proposed that this framework may become invisible to practitioners in its application over time, perhaps helping to explain why medical teachers pay little attention to it in routine practice. Norman, however, recently proposed another explanation for this observation suggesting that the teaching of the biosciences has traditionally been poor and thus the knowledge does not endure (Norman, 2012). Others have challenged the underlying approach that persisted throughout the $20^{\text {th }}$ Century that sees bioscience knowledge in any way separate from clinical knowledge (McColl et al., 2012). Malterud and colleagues have suggested that there have been too few qualitative studies of 'the art and science of clinical knowledge' for us to understand its form or construction (Malterud, 2001).

Thus there is a prevailing concern regarding the types of knowledge that medical students need and how that knowledge is acquired. It is one of the problems that persists despite decades of medical education reform (Bloom, 1989, Cooke et al., 2006). This study focused on medical teachers in hospitals with the aim of understanding the values they bring to their teaching which in turn affect how they go about teaching and how they think about themselves as teachers. These teachers are often omitted from the discourse despite their significant contribution to the teaching of medical students. For this reason, their perspectives and experiences seem to be less well appreciated than are the perspectives of teachers in other education sectors (MacLure, 1993, Pratt, 1998, Hammerness et al., 2005, Biggs and Tang, 2007, Entwistle, 2009).

This paper draws on a doctoral research project studying hospital-based medical teachers affiliated with the University of Melbourne. Three questions guided that research:

1. How do hospital-based medical teachers think about teaching?

2. How do they go about teaching?

3. How do they think about themselves as teachers? 
These questions generated new understandings of how they think about knowledge, pedagogy and their identities as teachers. The present paper focuses on the research findings in regard to the teachers' conceptualizations of clinical knowledge.

\section{Methodology}

The study group was constructed using a semi-purposive sampling strategy, working from medical student timetables at three hospitals to invite participating medical teachers who met the inclusion criteria. Teachers were invited to participate if they had completed their specialist training (that is, they were not residents, registrars or fellows), had taught students in both classroom and clinical settings, and did not have substantive related university appointments in medical education. This strategy did not therefore restrict participation to any particular age group, gender, nationality or medical specialty. The research intention was to generate an understanding of these teachers' values, perspectives and approaches by listening to them and seeing them in their everyday teaching work, finding and understanding the meanings they bring to the work of medical teaching in hospitals (Denzin and Lincoln, 2005). One researcher (JB) first observed each participant as they went about their teaching of medical students and subsequently interviewed each teacher (Table 1 outlines the questions asked in interviews).

Audio-recordings of the unstructured observations and semi-structured interviews were analysed by firstly systematically coding and categorising, and subsequently, through iterative interpretive processes, zooming in and zooming out from the data to the theory and back again (Wolcott, 1994). Triangulation was achieved through multiple data sources (interviews, observations and course documents), settings and methods as well as processes of cross-checking in the analysis and interpretation of the data. Triangulation was further achieved by interrogation of the internal qualities of the data and drawing on multiple theoretical perspectives for interpretations (Patton, 2002). The transferability (generalizability) of the findings can be considered by assessment of the typicality of the participants and the settings to see how the findings translate to other settings (Lincoln and Guba, 1985).

Students, patients and families were regarded as bystanders to the research. In each observed session, the researcher spoke to all bystanders providing an oral explanation of the purpose of the research and sought their approval to be present and to audio-record the teaching session. The research was approved by The University of Melbourne Human Ethics Research Committee and separately by the three hospitals' ethics committees. 


\section{Results}

The study was conducted with a group of 25 medical teachers at three hospitals associated with The University of Melbourne Medical School where students undertake traditional rather than longitudinal clerkships. The group included a sufficient spread of medical specialty, location, seniority and gender to encompass differences and constitute a study group that was not atypical. Saturation of the data was reached when 26 interviews and 34 observations had been conducted (Table 2 includes details of the participant group). In explaining and illustrating the findings, the participants are referred to as $\operatorname{Dr} A-\operatorname{Dr} Y$ and the source of the data is labelled as either [Interview] or [Observation].

In the interviews, all of the teachers talked more about the optimal forms of knowledge that are important for students than they talked about the form of the teaching itself. They frequently represented aspects of the knowledge they impart as 'real' knowledge. By implication, they suggest that there is other knowledge in medical education or in students' heads that is not real and needs to be transformed. These ideas about what constitutes 'real' knowledge, how it contrasts with other knowledge and the need to transform one into the other are discussed here with illustrative quotations from the interviews and observations.

\section{1. 'Real' knowledge}

\subsection{Knowledge of the real life of clinical practice: time, budgets and collegiality}

The importance of knowledge of real clinical life was variously expressed in the interviews. $\mathrm{Dr} \mathrm{N}$ explained that she thinks students can learn by being in 'real time' clinics where they get a sense of the time required to complete a consultation and the inevitability of the over-run of the allocated time per patient. Dr S referred to walking on a 'tightrope' in the allocated 12 minutes-per-patient in outpatient clinics and $\operatorname{Dr} A$ described how doctors get through their work by 'juggling' different responsibilities.

The observations of teachers in classroom and clinical settings revealed that this sense of time pressure was also conveyed directly to students. Teachers explained to students that they were rushed for time and could not cover everything in the topic, or that they could not stay after the tutorial or could not make the tutorial because of other administrative or clinical commitments. Also, in clinical teaching settings, they move quickly between and around patients and they subtly convey to students the pressure of time when they arrive late for the scheduled session. There is a strong physical sense of hurrying in and out of classroom and clinical situations, revealing to the students something of what they need to know about how the busy clinician's life is lived. 
In addition to the pressures of time, budgets and other 'real' life situations are part of this form of clinical knowledge. In referring back to the observed classroom tutorial, $\operatorname{Dr} \mathrm{D}$ mentioned that he gave students 'real world information'. He was referring to examples of the compromises that are sometimes required of him in his practice, the difference between the best and the affordable investigations or treatments to offer patients. Also, this knowledge includes awareness of the sensitivities inherent in particular consultations, sensitivities they need to learn to anticipate and manage. For instance, Dr D recounted for his students a story about a patient who exploited the opportunity that a consultation afforded to divulge intimate, incriminating personal information in the presence of his family. Dr D described this as one of those 'awkward' moments that he thinks students need to know about, coming to know what they will need to face as doctors. $\operatorname{Dr} A$ explained that by observing and practising in clinical settings (particularly in contrast to simulated settings) students have to consider how they 'will actually cope with it in real life, [to] have at least thought about [these issues] beforehand' [Dr A, Interview].

Other aspects of the doctors' work lives are revealed to students when they are watchful bystanders to collegiate discussions between doctors. They observe how doctors share information, problems and solutions with each other and with other health professionals. Observations in and around the outpatient clinic rooms, for instance, revealed the nature of professional relationships that students have an opportunity to learn about. Before starting a consultation, or sometimes between patients or even during a consultation, doctors often called on each other for assistance (with computers and software) and input (with clinical matters and decisions). In the interviews, some teachers mentioned that one of the motivations for teaching in public hospitals is the opportunity for contact with medical colleagues. Thus, from early in their clinical rotations in hospitals and other practice settings, students come to know that these doctor-to-doctor interactions are a common and positive feature of hospital work life, and the subtleties of the interactions suggest that sometimes they provide a momentary relief from concentrated patient contact and clinical work. (Others have presented these interactions as 'interruptions' to teaching and learning on the wards and proposed 'protected' and 'uninterrupted' teaching time as an ideal (Young et al., 2009, p. 815)).

\subsection{Knowledge from the real places in hospitals: near patients and in corridors}

Other references to 'real' suggest a perspective that clinical knowledge resides in the places of the hospital - around the patient's bedside, in the clinic or ward and in the corridors. This finding is in line with a new interest in spatiality and place in the broader field of education and workplace learning (Fenwick and Edwards, 2010, Mulcahy, 2006). 
After observing a tutorial with a group of students for one hour near but not actively involving the patient, the researcher (JB) was prompted to ask the Intensive Care Unit (ICU) doctor why he conducted the tutorial there rather than in a nearby, unoccupied tutorial room. He reflected:

... I think it makes it more real ... I think from my own experience of being taught was I learnt a lot more at the bedside, I learned from people who liked to involve me in the conversation and made it seem real ... sometimes also at the bedside there's all the data too so we often pull up an $x$-ray as we did there and look at some of the other results as well, the blood gases and things. So there's a convenient practical element at the bedside as well because all the data is there. [Dr K]

In other words, it seems to be both concrete and conceptual knowledge that determines the teacher's preference to teach there. This teacher's reference to 'real' here (and then elsewhere in the interview) was of particular interest to the research because it was co-located with his descriptions of the teaching as actively 'involving' students and, later, as a somehow facilitating a 'conversation'. These descriptions were surprising because the tutorial consisted mostly of the teacher talking. It was not a conversation - the students were mostly listening, occasionally looking at the data on the computer monitor and occasionally answering a question. But for the teacher, being in the place itself seems to involve them, to provide them with knowledge - as they stand listening, often awkwardly and uncomfortably, amidst the busy workplace where nursing, administrative, domestic and other medical staff go about their work. The student-teacher group stood only metres from the patient (and his mother), a critically-ill man of the students' own age. The sense is that the place itself acts on students' knowledge.

The corridors of hospitals are also regarded as powerful sources of knowledge. Research observations during the study found that corridors are often chosen as the places for teaching. In conducting the observations for this study, JB found herself in crowded gatherings in corridors as the traditional between-patient information-sharing takes place during ward rounds. As in the ICU tutorial described above, some of these gatherings took place only a few metres from an unoccupied meeting/seminar room despite the inconvenience caused by the corridor gathering to patients, visitors and domestic staff who negotiate their passage and their tea-trolleys around the medical team. Corridors are also noisy, and students are often awkwardly straining to listen, watch and take notes - and sometimes to ask a question. 
At the same time, all of this bustling human activity makes the corridor a lively place that connects students with the specialist as teacher to learn about medicine. $\mathrm{Dr} \mathrm{M}$ offered an animated account of that exciting 'opportunistic stuff' that corridors contain:

... the other day I was walking to ED there was a patient with a heart attack and there was a student standing in the corridor and I said 'want to see a heart attack?' and 'yes' and it was one of the final years I had just taken them the day before, so I took her with me. [Dr M, Interview]

In collecting the observation data for this study, JB spent long periods of time with students waiting in and traversing the corridors both with and without the teacher. In considering the ways that teachers represented these places, combined with our own observations in practice of the many verbal and non-verbal interactions in doorways, lifts and other spaces, knowledge does seem to be available to learners there.

\subsection{Knowledge of people}

In the interviews with teachers in all age groups, all medical specialties and both males and females, the teachers emphasized that central to what clinicians need to know in order to do their work is knowledge of patients as real people and how to interact with them. There are two aspects to this finding. First, students need to learn how to think about patients as individuals, as having specificity, being different from each other. In Dr A's terms, this is 'the person sitting in front of you' and Dr F refers (somewhat carelessly perhaps) to 'what walks through the door'. The emphasis here is on the ways that patients are different from each other and how 'real' knowledge is different from formal, knowledge and theory:

Every patient is different, there's all these things to consider ... and what might be right for one patient might not be right for the other ... [Dr J, Interview]

And $\operatorname{Dr} \mathrm{G}$ was more specific about the need to highlight this for students:

if you get someone who lives on the street your solution might be different than for someone who lives in a house with carers coming in. So that kind of dynamic is what I want them to think about - beyond just learning the facts of the case. [Dr G, Interview]

Second, students need to learn not to think of patients as 'just diagnoses' [ $\operatorname{Dr} A]$. That is, they need to learn to treat people as human beings not objects, and to learn what appropriate interpersonal responses look and sound like in different care settings. In intensive care, for example: 
... whenever we examine a patient I will get them to tell the person what they're going to do, I'll say maybe you can examine their conscious state, look at their eyes, but before you do that you're going to say to them, even though they look unconscious 'Sir, I'm just going to shine a light in your eye'. So there's always that personal element there, showing some respect rather than just going and doing [Dr K, Interview]

Emerging here is the sense that sick or very sick, competent or demented, conscious or unconscious, patient care requires finely grained knowledge of what constitutes respectful behaviour in each specialty. Here is a rich sense of what is not conveyed by the commonplace term 'communication skills'. All of the medical teachers emphasized the point that students need knowledge of how to behave around and towards patients.

In addition, other teachers emphasized the importance 'the broader aspects of medicine', something 'broader than the acquisition of knowledge' - or, the generic, 'professionalism' [Dr A]. Dr R said students need to be taught 'patient care ... introducing the patient and introducing the team to the patient' because otherwise students (and young doctors) 'just don't do that, [they] stand in front of the patient and talk about them as if they aren't participating'. While the common term 'communication skills' accents the 'doing', the teachers emphasized that respectful communication needs to be observed and learned 'about', learned as part of the broader domain of knowledge about patients as people.

2. The comparison with bio-science/textbook knowledge/theoretical knowledge The teachers highlighted the contrast between the characteristics and sources of 'real' knowledge and the knowledge that they see students bringing to the hospitals, knowledge gained from textbooks and bioscience lecturers. They see this knowledge represented in the tutor/course guides they are sent from the University and in the students' approaches to learning, and they see it as inadequate, in the wrong form and even misleading.

Firstly, the students' knowledge is thought to be inadequate because 'I don't think they get taught nearly as much' as students were taught in the past [Dr D]. The second reason for devising their own tutorials is that they think the students are no longer taught 'the basics of the illnesses and antibiotic sensitivities and bacteria and that sort of stuff' so clinical teachers have to teach the basics as well as 'the clinical signs and clinical presentations' [Dr F].

Another criticism of the students' knowledge emerges in the teachers commonly being dismissive about 'textbooks'. The problem with textbook knowledge seems to be that it takes the form of generic and de-contextualized lists which may be out of date or incorrect. Information presented as 
'lists' gives students knowledge consisting of 'beautiful lists' but nothing of 'value' in diagnosing and managing patients [Dr E]. Lists are also seen to be hard to learn, even recalled as making the learning of some medicine horribly tedious [Dr D]. In the interview, $\operatorname{Dr} Q$ related quite a long story about being caught out in her early medical practice by acting on incorrect information gained from a textbook, and this seemed to justify her mistrust of textbooks. Textbooks were talked about not providing the real stuff about 'how the specialist decides' which drug to give, or even just how to 'tell the difference' between drugs [Dr G]. In the 'real' world, clinical decisions are made on behalf of an individual patient - not based on a generic list of medications applied to composite, idealized patients in textbooks [Dr A].

In the interviews, textbooks were presented by eight of the teachers as teaching 'knowledge' but not how to 'think'. Books are useless for the 'struggle' of clinical practice, and do not help with the 'uncertainties' that arise in dealing with patients [Dr A]. Books seem not to contribute to students learning to think well: they arrive in hospitals with the mistaken view that they have 'right' answers - or even 'that there are right answers!' [Dr Q]. In referring back to instances in the tutorial which the researcher had previously observed, teachers described students as giving textbook answers without thinking [ $\mathrm{Dr} C$ ], giving 'kneejerk' responses to questions [ $\mathrm{Dr} \mathrm{S}]$, and giving answers which are even just 'silly' [ $\mathrm{Dr} \mathrm{Q}]$. All but one of the teachers blamed textbooks for these problems, and by implication, the formal curriculum.

Consequently, working from the view that the knowledge students bring from the University is not the right knowledge, a number of teachers tamper with the formal curriculum. $\operatorname{Dr} B$ said 'I have my feelings about what I want to tell them' and this 'feeling' determines the content for her lecture. Others are prepared to contradict the formal curriculum:

I'm probably not doing what I'm supposed to do ... I ... want to transmit something that I think is important ... [Dr Q, Interview]

Even more pointedly than these declarations, $\operatorname{Dr} \mathrm{O}$ was heard to tell the students that he was not going to teach the university's curriculum. When he explained to them that 'they' (that is, the university) had asked him to teach a whole unrealistically long list of things related to his specialty, he reassured them '... so l'll just touch on what I would regard as being important things for you' [Dr $\mathrm{O}$, Observation]. The students sighed, teacher and students thus allies with a shared understanding of what knowledge is valuable. 
It seems that these teachers exert their authority to teach because, in their terms, they know what knowledge is required for practice and take every opportunity to provide students with access to it. Each of them is teaching about the specialty area of medicine they practice - how to take a history from a child, from a patient with dementia, from a diabetic about a 'hypo'. JB also noticed how the teachers introduced themselves to students: 'I'm a Paediatrician', 'I'm a Neurologist' or 'I'm an Endocrinologist'. Their sense of authority to teach seems to arise from their specialty medical knowledge, layers of knowledge from practice with one patient after another in that specialty. As the examples above suggest, even knowledge of the way to behave around patients is often knowledge essential to the specialty rather than general clinical knowledge.

In the same way that the textbook 'lists' are denigrated, so too are the lists and instructions in the tutor guide, a document representing the formal curriculum. The Haematology teacher sees the lists as 'extremely broad ... a whole lot of technical stuff' [Dr D] so he does something more practical in his tutorial. And, $\operatorname{Dr} M$, immediately following his animated reference to having met a medical student in the corridor and the excitement of taking her to a dramatic clinical event with him, continues to make the contrast:

I don't like the rigid, you'll do this and prepare like this. I don't like that because I was never taught that way and I don't think I'm very good at it because I don't have the time to prepare for it. I don't want it. That [tutor guide] is filed in there somewhere [gesticulates dismissively towards his filing cabinet]. [Dr M, Interview]

The lists are too long and too rigid, as are the tutor guides themselves. Not only are these guides wrong in form, they seem to be wrong in intent. The list of what to teach presents a fixed view of the knowledge in the doctor's specialty that is not familiar to or comfortable for him. As well, it would also require him to teach differently from the ways he learned the specialty and the ways he has worked out for teaching it to the students.

Furthermore, the teachers also characterized classrooms as inadequate, contributing to the making of the wrong type of knowledge. These (and other clinical teachers we work with) often choose not to teach in classrooms as though the places themselves are part of the problem. In this study, classrooms were represented by some teachers as antithetical to the teaching and learning that they value. Various comments suggest that classrooms mean students are 'just sitting', 'recipients', 'in a coma', 'sleepy', 'nod off', just 'just blah blah blah', 'just listening and going [mimes sleepiness]'. Like textbooks these places are dull and dulling; they seem to take the vitality out of the knowledge. 
3. A different kind of knowledge: Knowledge transformed

Knowing that valuable knowledge is characteristically messy, multi-faceted, fluid and dynamically interconnected making it unique and essential for practice, the teachers contrast it favourably with knowledge that they see as static, orderly and about ideals rather than realities, the teachers' agenda is to transform one form of knowledge into another - 'as soon as they hit the hospitals' [Dr A].

One transformation process is doing lots of 'little things' to make the knowledge right: showing students, 'little clinical tricks', highlighting 'little important things' and 'little details that make things go smoother', and sharing 'little bit of philosophy about how to think about' a certain condition. Another process involves 'undoing' students' knowledge before it can be remade. Two specialists [Dr $\mathrm{Q}$ and $\mathrm{Dr} \mathrm{S}$ ] explained, by referring back to instances in the observed sessions, that they often need to expose 'silly answers' and 'wrong thinking' in students. They both expressed some impatience with students' inability to call up useful knowledge, to think sensibly about a patient, a question or a scenario. Furthermore, $\operatorname{Dr} \mathrm{X}$ named a key objective in her lecture as wanting to 'undo' some wrong thinking that students have acquired from what others have taught them. More generally, and perhaps reflecting a more informed educational perspective, Dr F explicitly described one of his early moves in the tutorial is to deal with students' 'misconceptions' about particular aspects of medicine and practice.

In addition to fixing and doing little things, teachers see themselves involved in making bridges, links and connections that transform (or help the students transform) one form of knowledge into another. Dr W talked about her experience as a medical student where it 'came together', and sees her job in OP is to 'put it together for them' and the teacher is always 'putting it together quickly'. The teacher must act at the beginning of the Outpatient clinic session, as well as between patients, so that students are orientated to and can then get meaning out of each consultation, understanding 'the whole link'. $\operatorname{Dr} \mathrm{C}$ talked about putting things together and making connections as a higher order purpose:

'... perhaps trying to make it about the art of medicine as opposed to the science of it all, you know putting together the clinical and the investigation and make the connection' [ $\mathrm{Dr} \mathrm{C}$, Interview].

Central to these knowledge transformation processes is the patient. The teachers emphasized what is also called for in the literature: the need for stronger links between clinical and other learning. Interestingly, however, the teachers suggest that these links are already subtly, variously, but persistently occurring and they are determinedly committed to the processes. All except two 
teachers [ $\mathrm{Dr} \mathrm{O}, \mathrm{Dr} \mathrm{I}]$ discussed an aspect of clinical knowledge being formed around and in relation to patients. There are four expressions of this understanding of clinical knowledge being fundamentally made around patients: the patient is put into context (the teacher explains the patient's history to enable the student to understand 'today's visit), patients make knowledge messy (blood-thinning medication is necessary but the patient is determined to keep cycling), patients have knowledge that doctors need (ask the patient where she was when she had her ' $h y p o$ ' rather than doing a test for it). The fourth expression is the belief that knowledge made around patients is the knowledge that they can call on throughout a professional lifetime, a belief that "I'll never forget this" [Dr M] or "I can still remember interesting patients that I saw as a student [after 40 years]" [Dr R]. As well, constructed this way, knowledge appears to be in the form of 'perspective' and 'wisdom', the higher realms of clinical knowledge.

\section{Discussion}

This study focused on medical teachers in hospitals with the aim of understanding the values and perspectives they bring to their teaching and ways these affect their approaches to teaching. Twenty five teachers from three hospitals associated with one university were observed in interaction with medical students in classroom and clinical settings and then interviewed. The authors acknowledge that the transferability of the findings may be limited by the context of the study particularly the different arrangements that exist for teaching and the relationships between medical teachers in hospitals and universities around the world. In addition, if a similar study were conducted with junior doctors, it is possible that other conceptualizations of clinical knowledge may have been found.

We found that at the core of the teachers' conceptualizations of teaching, is a distinctive way of thinking about clinical knowledge as messy, multi-faceted, fluid and dynamically interconnected. They gave particular emphasis to this knowledge being 'real' - it is knowledge about real life, constructed with real people and in real places. Theory in relation to professional life, places, patients and interpersonal interactions is seen to derive from observation, practical experience and reflection as well as from research.

Two decades after Irby classified the domains of clinical knowledge that teachers need as explained at the start of this paper(Irby, 1994). The teachers in this study have offered a new way of thinking about the nature of knowledge they have - and the knowledge students need, and their values, practices and passions add texture and vitality to that model. First, the teachers' perspectives suggest that there is value in referring to clinical 'knowledge' rather than to clinical 'experience' as in the Irby model. For the teachers, clinical knowledge seems to emerge out of clinical experience(s) and this distinction is important when the aspects of knowledge, the making of the knowledge and 
the teaching of knowledge are being considered. Second, the teachers did not distinguish between knowledge and skills. Even in relation to 'communication', their focus was not on 'skills' (the doing) but on what the students need to know about how to behave around patients in a range of situations. This perspective is consistent with a holistic view of professional knowledge incorporating procedural, propositional, practical, tacit, skills and know-how (Eraut, 2004, Eraut, 1994).

As well, the findings here suggest a new perspective on the common but complex notion of learning from patients (Henriksen and Ringsted, 2014). The teachers did not talk of the more commonplace learning 'about' or even 'with' patients (Nair et al., 1998); rather, they suggested that the knowledge is in patients. From this perspective, we can no longer see knowledge as residing solely in the doctor or in the student. This re-positioning of the patient as a central source of clinical knowledge contributes to the contemporary re-thinking of the relationship between patient and doctor (and between patient and student) and connects with the notion of a re-distribution of power in medicine (Bleakley et al., 2011). According to that understanding, students learn 'with' rather than just 'about' patients (Rees et al., 2007, Towle and Godolphin, 2011) but our study highlights an additional requirement for respect of the patient as a tacit holder of essential clinical knowledge.

Our study has also shown that it is not only the patient who can be re-positioned as a source of clinical knowledge. The places where clinical practice, teaching and learning happen are also newly positioned, seen to offer more than a 'context' or 'container' for the teaching and learning to occur (Dornan et al., 2007, Edwards and Miller, 2007, Teunissen and Wilkinson, 2011). The new understanding is that being around patients and being in places means gaining knowledge from them, connecting to the concept of 'distributed intelligence' (Cooke et al., 2010). Viewed through the Actor Network lens now emerging in medical education (Bleakley, 2012, Bleakley et al., 2011), the clinical place emerges as another (non-human) actant. The teachers' perspective is resonant with contemporary understandings of the knowledge-place relationship where the place is no longer just 'a backdrop against which action takes place' (Mulcahy, 2006, p. 58). If this line of thinking is pursued, the teachers can be seen to evoke a less dichotomous view of content and context than is often suggested in the literature. For instance, previously it has been suggested that 'medical educators have largely ignored the importance of location' (Jolly and Rees, 1998, p. 184), and that they have focused on teachers and pedagogy 'rather than on the contexts for such activities' (Bleakley et al., 2011, p. 137).

There are two broad practical implications of this new understanding of the constituents of clinical knowledge. First, there is a need to consider the materials associated with the curriculum and to retune them more finely to the teachers' understanding of clinical knowledge and of their place in it. 
This new conceptualisation then needs to be promoted widely. Currently, the essential richness and messiness of clinical knowledge are missing from documents and discussions related to the curriculum as are the teachers' perceptions of their unique contributions to the students' acquisition of this knowledge. From their perspectives, detailed and definitive lists belong to bioscience knowledge and textbooks, so other textual styles will be needed to capture the rich life-breath of tacit knowledge that is at the heart of clinical practice and at the core of their identities as teachers. Both documents and discussions need to represent and explicitly value the knowledge that is uncertain, disordered, unwritten, interconnected and fluid. At the same time, however, formal representations in documents and discussions need to preserve the essential vitality that distinguishes clinical from bioscience knowledge. This is a curriculum-writer's challenge. It is not a content or organisational challenge but the challenge of capturing in words and graphics the qualities of the knowledge and knowledge-making processes as these are understood by the teachers..

The finding that place is important to teachers also has practical implications. The teachers do not ignore location, but rather, they actively choose to teach in the places they judge to be productive for constructing knowledge with the characteristic vitality they value. This new understanding could assist teachers and course administrators in making more education-based decisions related to when teaching does and does not need to occur in clinical places. It could be a principle that informs their decisions about the level and frequency of 'the dose' of clinical places that is required for effective learning in each clinical field. It also suggests new considerations for the emerging research interest in hospital-based learning environments (Bines and Jamieson, 2013).

In addition to the findings related to the nature of clinical knowledge, we found that these teachers have a particular understanding of the relationship between different forms of medical knowledge. In contrast to the common description of how the components of medical knowledge are related is that they are 'integrated' (Cooke et al., 2010, Irby, 1994). However, the teachers offer a sense of something different from 'integrated' and this perspective affects how they practice as teachers. They employed metaphors of 'links' and 'bridges', and their expressions of 'putting' and 'pulling' together formal bioscience knowledge and clinical knowledge of knowledge, and this suggests something more subtle, certainly more dynamic and continuous than is implied in 'integrated'. Located within this perspective on knowledge relationships, we found the teachers were frequently dismissive of formal (codified) knowledge (encompassing both textbook and bioscience knowledge). This attitude to formal knowledge can be explained by existing models (Patel et al., 1989, Rikers et al., 2005, Woods, 2007), and even, perhaps, seen to be a result of the traditionally poor teaching of 
formal knowledge that makes it hard to recall (Norman, 2012). However, there are convincing alternative explanations in the field of the sociology of education and the sociology of knowledge.

The doctors' preference for dismissing formal knowledge can be seen as reflecting a legitimate understanding of the very structure of knowledge (Young, 2008). Young builds on Bernstein's distinction between 'vertical' knowledge (general, explicit, coherent and expressed in bodies of codified knowledge, not flexible) and 'horizontal' knowledge (on-the-job or work-based, acquired experientially, flexible) (Bernstein, 2000) 'Vertical' knowledge cannot be derived from 'Horizontal' knowledge, and 'Horizontal' knowledge cannot be made explicit because its power resides in its very tacit-ness. Furthermore, according to this theoretical perspective, it is not possible to apply 'Vertical' knowledge directly to specific everyday workplace realities because the type of knowledge needed is that which is sufficiently flexible to deal with immediate practical problems. Seen through this lens, the medical teachers in our study seem to have an understanding of knowledge structures, that the knowledge they have and value is in essence different from formal knowledge - and that the two can be linked or bridged but cannot be integrated. This resonates with a recent argument that the contemporary efforts at course design or program operation level to integrate different forms of knowledge are misguided (Kulasegaram et al., 2013). Thus, at both a knowledge structure level and a cognitive level, the notion of integrating different forms of medical knowledge is contested. At a practical level, this contest is played out where the curriculum is being implemented by medical teachers in hospitals.

\section{Conclusion}

This study draws attention to the importance of acknowledging hospital-based teachers' perspectives on clinical knowledge and the teaching of that knowledge to medical students. In particular, the study suggests for the importance of respecting and affirming the priority that the clinical teachers give to the teaching and learning of a distinctive form of knowledge. Because it is at the core of their thinking about teaching and about themselves as teachers, their conceptualisation of clinical knowledge needs to be captured and explicitly valued in the documents and discourse associated with medical curriculum. It is also important that this appreciation becomes institutionalized as a principle for any professional development associated with physicians' and surgeons' roles as teachers.

\section{Acknowledgements}

We acknowledge the doctors who gave their time to participation in this study and to Professor Dan Pratt for his critical comments on the presentation of the findings in the doctoral dissertation. 


\section{Table 1: Interview Questions}

1. It was good to see that teaching session. How typical was it?

2. How would you broadly describe what it is that you were doing in that session?

3. Something I noticed when you were teaching in that session was [describe the behaviour observed]. Can tell me more about that and perhaps why you do it that way/why it happened that way?

4. Do you think of yourself as a teacher?

5. What have been the main influences on you as a medical teacher and how/what you teach?

6. What else is it important for me to know about being a medical teacher? What have I missed?

7. Thank you (and further arrangements). 
Table 2: Details of sites, participants and data collection information

\begin{tabular}{|c|c|}
\hline Three public hospitals & Participants \\
\hline Large, general, suburban & 7 \\
\hline Medium, general, outer suburban & 12 \\
\hline Large, specialist, central metropolitan & 6 \\
\hline \multicolumn{2}{|l|}{ Participants* } \\
\hline Physicians & 18 \\
\hline proceduralists (surgeons \& procedural physicians) & 7 \\
\hline \multicolumn{2}{|l|}{ Interviews $* *$} \\
\hline number & 26 \\
\hline duration & $11 \mathrm{hrs}$ \\
\hline average duration & 25 mins \\
\hline \multicolumn{2}{|l|}{ Observations $* * *$} \\
\hline number & 34 \\
\hline total hours & 36 \\
\hline \multicolumn{2}{|l|}{ Observation settings - medical student teaching in: } \\
\hline Lectures ( 40 students) & 7 \\
\hline Classroom tutorials & 15 \\
\hline Bedside tutorials & 4 \\
\hline Outpatient clinic teaching & 4 \\
\hline Ward round teaching & 4 \\
\hline
\end{tabular}

\section{Notes to Table 2:}

* The group of participants includes physicians from the following specialties: neurology, respiratory medicine, infectious diseases, paediatrics (general and sub-specialties), geriatrics, endocrinology, haematology, renal medicine, general medicine and emergency medicine. The group of proceduralists includes doctors from the following specialities: specialist surgery, cardiology, intensive care and ophthalmology. The teachers were in the 35-65 age range and all had consultant (not resident/trainee) positions at the hospitals. They all taught undergraduate medical students from UoM in clinical and classroom settings. 
** One participant did not respond to the invitation to an interview subsequent to the observed teaching session. The original plan was to interview each participant twice, once following each of two observed teaching sessions. However, after conducting two interviews with two participants, this method was deemed to be both inconvenient for the teacher and the second interviews generative of little new data.

All teachers who volunteered to participate were expected to be available for observation of both classroom and patient-based teaching. However, while all of the participating teachers do teach in both settings, the teaching was not always timetabled to occur in one term, or even in one year in which the study was being conducted. Thus not all teachers were observed in both settings. 


\section{References}

BERNSTEIN, B. (2000) Pedagogy, Symbolic Control and Identity: Theory, Research, Critique, Oxford, Rowman and Littlefield.

BIGGS, J. \& TANG, C. (2007) Teaching for Quality Learning at University: What the student does, Berkshire, Open University Press.

BINES, J. E. \& JAMIESON, P. (2013) Designing new collaborative learning spaces in clinical environments: experiences from a children's hospital in Australia. Journal of Interprofessional Care, 27, 63-68

BLEAKLEY, A. (2012) The proof is in the pudding: Putting Actor-Network-Theory to work in medical education. Medical Teacher, 34, 462-467.

BLEAKLEY, A., BLIGH, J. \& BROWNE, J. (2011) Medical Education for the Future: Identity, power and location, London, Springer.

BLOOM, S. W. (1989) The medical school as a social organization: The sources of resistance to change. Medical Education, 23, 228-241.

COOKE, M., IRBY, D. M. \& O'BRIEN, B. C. (2010) Educating Physicians: A call for reform of medical school and residency, Stanford, Jossey-Bass.

COOKE, M., IRBY, D. M., SULLIVAN, W. \& LUDMERER, K. M. (2006) American Medical Education 100 Years after the Flexner Report. The New England Journal of Medicine, 355, 1339-1344.

DE BRUIN, A. B. H., SCHMIDT, H. G. \& PIKERS, R. M. J. P. (2005) The role of basic science knowledge and clinical knowledge in diagnostic reasoning: A structural equation modeling approach. Academic Medicine, 80, 765-773.

DENZIN, N. K. \& LINCOLN, Y. S. (2005) Introduction: The discipline and practice of qualitative research. IN DENZIN, N. K. \& LINCOLN, Y. S. (Eds.) The Sage Handbook of Qualitative Research. 3rd ed. Thousand Oaks, Sage.

DORNAN, T., BOSHUIZEN, H. P., KING, N. \& SCHERPBIER, A. (2007) Experience-based learning: A model linking the processes and outcomes of medical students' workplace learning. Medical Education, 41, 84-91.

EDWARDS, R. \& MILLER, K. (2007) Putting the context into learning. Pedagogy, Culture and Society, 15, 263-274.

ENTWISTLE, N. (2009) Teaching for Understanding at University, London, Palgrave Macmillan.

ERAUT, M. (2004) Informal learning in the workplace. Studies in Continuing Education, 26, 247-273.

ERAUT, M. E. (1994) Developing professional knowledge and competence, London, Falmer Press. 
FENWICK, T. \& EDWARDS, R. (2010) Actor-Network Theory in Education, Abingdon, Routledge.

GOLDSZMIDT, M., MINDA, J. P., DEVANTIER, S. L., SKYE, A. L. \& WOODS, N. N. (2012) Expanding the basic science debate: the role of physics knowledge in interpreting clinical findings. Advances in Health Science Education, 17, 547-555.

HAMMERNESS, K., DARLING-HAMMOND, L., BRANSFORD, J., BERLINER, D. C., COCHRANE-SMITH, M., MCDONALD, M. \& ZEICHNER, K. (2005) How teachers learn and develop. IN DARLINGHAMMOND, L. \& BRANSFORD, J. (Eds.) Preparing teachers for a changing world: What teachers should learn and be able to do. San Fransisco, Jossey-Bass.

HENRIKSEN, A. \& RINGSTED, C. (2014) Medical students' learning from patient-led teaching: experiential versus biomedical knowledge. Advances in Health Science Education, 19, 7-17.

IRBY, D. M. (1994) What clinical teachers in medicine need to know. Academic Medicine, 69, $333-$ 342.

JOLLY, B. C. \& REES, L. (1998) Medical education in the millenium, Oxford, Oxford University Press.

KULASEGARAM, K. M., MARTIMIANAKIS, M. A., MYLOPOULOS, M., WHITEHEAD, C. R. \& WOODS, N. N. (2013) Cognition before curriculum: Rethinking the integration of basic sciences and clinical learning. Academic Medicine, 88, 1578-1585.

LINCOLN, Y. S. \& GUBA, E. G. (1985) Naturalistic inquiry, Newbury Park, Sage.

MACLURE, M. (1993) Arguing for your self: Identity as an organising principle in teachers' jobs and lives. British Educational Research Journal, 19, 311-322.

MALTERUD, K. (2001) The art and science of clinical knowledge: evidence beyond measures and numbers. The Lancet, 358, 397-400.

MCCOLL, G. J., BILSZTA, J. \& HARRAP, S. (2012) The requirement for bioscience knowledge in medical education. Medical Journal of Australia, 196 1-4.

MULCAHY, D. (2006) The salience of space for pedagogy and identity in teacher education: Problembased learning as a case in point. Pedagogy, Culture and Society, 14, 55-69.

NAIR, K., COUGHLAN, J. L. \& HENSLEY, M. J. (1998) Impediments to bedside teaching. Medical Education, 32, 159-162.

NORMAN, G. (2012) The basic role of basic science. Advances in Health Science Education, 17, 453456.

PATEL, V. L., EVANS, D. A. \& GROEN, G. J. (1989) Reconciling basic sciences and clinical reasoning. Teaching and Learning Medicine, 1, 116-121.

PATTON, M. Q. (2002) Qualitative research and evaluation methods, Thousand Oaks, Sage.

PRATT, D. D. (1998) Five perspectives on teaching in adult and higher education, Malabar, Krieger Publishing. 
REES, C. E., KNIGHT, L. V. \& WILKINSON, C. E. (2007) Doctors being up there and we being down there: A metaphorical analysis of talk about student/doctor-patient relationships. Social Science and Medicine, 65, 725-737.

RIKERS, R. M. J. P., SCHMIDT, H. G. \& MOULAERT, V. A. (2005) Biomedical knowledge: encapsulated or two worlds apart? Applied Cognitive Psychology, 19, 223-231.

TEUNISSEN, P. W. \& WILKINSON, T. J. (2011) Learning and teaching in workplaces. IN DORNAN, T., MANN, K., SHERPBIER, A. \& SPENCER, J. (Eds.) Medical education: Theory and practice. Edinburgh, Churchill Livingstone.

TOWLE, A. \& GODOLPHIN, W. (2011) Patient involvement in health professional education. IN DORNAN, T., MANN, K., SHERPBIER, A. \& SPENCER, J. (Eds.) Medical education: Theory and practice. Edinburgh, Churchill Livingstone.

VOSTI, K. L., BLOCH, D. A. \& JACOBS, C. D. (1997) The relationship of clinical knowledge to months of clinical training among medical students. Academic Medicine, 72, 305-307.

WOLCOTT, H. F. (1994) Transforming Qualitative Data: Description, analysis, and interpretation, Thousand Oaks, Sage.

WOODS, N. N. (2007) Science is fundamental: The role of biomedical knowledge in clinical reasoning. Medical Education, 41, 1173-1177.

YOUNG, L., ORLANDI, A., GALICHET, B. \& HEUSSLER, H. (2009) Effective teaching and learning on the wards: easier said than done? Medical Education, 43, 808-817.

YOUNG, M. F. (2008) Bringing Knowledge Back In: From social constructivism to social realism in the sociology of education, Abingdon, Routledge. 